Article

\title{
Optimal Design of a Tower Type SCR-deNO Facility for a 1000 MW Coal-Fired Power Plant Based on CFD Simulation and FMT Validation
}

\author{
Haojun Zeng ${ }^{\circledR}$, Jingqi Yuan * and Jingcheng Wang \\ Department of Automation, Shanghai Jiao Tong University, and the Key Laboratory of System Control and \\ Information Processing, Ministry of Education of China, 800 Dongchuan Road, Shanghai 200240, China; \\ tsang000@sjtu.edu.cn (H.Z.); jcwang@sjtu.edu.cn (J.W.) \\ * Correspondence: jqyuan@sjtu.edu.cn; Tel.: +86-(0)21-3420-4055
}

Received: 12 February 2019; Accepted: 7 March 2019; Published: 11 March 2019

\begin{abstract}
Selective catalytic reduction (SCR) is one of the most efficient methods to reduce $\mathrm{NO}_{x}$ emissions from coal-fired power plants. This paper deals with an optimal design tower type SCR-deNO ${ }_{x}$ facility for a $1000 \mathrm{MW}$ coal-fired power plant. Combined with computational fluid dynamics (CFD), the configuration of the baffles geometry was studied with spatial constraints. Flow field was regulated at the ammonia injection grid (AIG) with the dual aim of reducing difficulties in implementing the non-uniformed ammonia $\left(\mathrm{NH}_{3}\right)$ injection strategy and achieving a more homogeneous distribution at the catalyst entrance. A flow model test (FMT) was carried out at a laboratory scale to verify the design results. The results of the flow model test are in good agreement with the computational fluid dynamics. It is indicated that small-sized baffles are recommended for installation at the upstream side of the facility as the optimal design and ability to regulate the flow field at the ammonia injection grid makes it an effective way to deal with spatial constraints. This paper provides a good reference for optimizing the tower type SCR-deNO $\mathrm{S}_{x}$ facilities with spatial constraints.
\end{abstract}

Keywords: selective catalytic reduction (SCR); tower type SCR-deNO $\mathrm{S}_{x}$ facility; computational fluid dynamics (CFD); flow model test (FMT); spatial constraints

\section{Introduction}

Emission of nitrogen oxides $\left(\mathrm{NO}_{x}\right)$ will lead to severe environmental problems. $\mathrm{NO}_{x}$ is considered to be responsible for the formation of photochemical smog, acid rain, tropospheric ozone, ozone layer depletion, and a variety of health problems for human beings [1-3].

Selective catalytic reduction (SCR) technology is one of the most efficient approaches to reduce $\mathrm{NO}_{x}$ emissions [4-6]. Reductants such as urea or ammonia $\left(\mathrm{NH}_{3}\right)$ are injected into the flue gas from an ammonia injection grid (AIG) [7-9]. The typical SCR reactions include [10,11]:

$$
\begin{gathered}
4 \mathrm{NO}+4 \mathrm{NH}_{3}+\mathrm{O}_{2} \rightarrow 4 \mathrm{~N}_{2}+6 \mathrm{H}_{2} \mathrm{O} \\
4 \mathrm{NO}+6 \mathrm{NH}_{3} \rightarrow 5 \mathrm{~N}_{2}+6 \mathrm{H}_{2} \mathrm{O}
\end{gathered}
$$

The SCR-deNO $\mathrm{O}_{x}$ efficiency is influenced by reaction temperature, residence time, space velocity, and the uniformity of both flue gas velocity and $\mathrm{NH}_{3}$ concentration [12,13]. Therefore, to achieve high $\mathrm{NO}_{x}$ reduction efficiency and low $\mathrm{NH}_{3}$ slip, optimal design of the flow field and non-uniformed $\mathrm{NH}_{3}$ injection strategy should be carried out for the SCR-deNO ${ }_{x}$ facilities [14]. 
The SCR-deNO ${ }_{x}$ facilities are usually divided into $\pi$ type and tower type according to their overall shapes. So far, many studies have been conducted on the optimization of flow field for the $\pi$ type SCR-deNO $\mathrm{S}_{x}$ facilities. The baffles geometry and the corresponding configuration have been investigated [15-17]. Attempts have also been made to reduce difficulties in performing the non-uniformed $\mathrm{NH}_{3}$ injection strategy and to achieve a more homogeneous distribution of $\mathrm{NH}_{3}[18,19]$. However, research on the optimal design of the tower type SCR-deNO $\mathrm{N}_{x}$ facilities are scarce. A tower type SCR-deNO $\mathrm{S}_{x}$ facility usually has fewer turnings and a huge expansion duct, which implies a large sectional area and less turbulence. Nowadays, with an increasing number of tower type SCR-deNO $x$ facilities $[20,21]$, it is necessary to implement flow regulation and ensure optimal design. In the meantime, spatial constraints are common due to the compact configuration. Hence, it is more challenging to find an effective way to optimize the tower type SCR-deNO facilities. $^{2}$

Computational fluid dynamics (CFD) simulation is nowadays commonly applied to the flow field regulation of SCR-deNO ${ }_{x}$ facilities [22,23]. In this paper, the optimal design of the tower type SCR-deNO ${ }_{x}$ facility for a $1000 \mathrm{MW}$ coal-fired power plant is presented. A combination of crossed baffles and small-sized arc-shaped baffles are used to deal with the spatial constraints and to regulate the flow field. The influence of flow regulation at the AIG is evaluated. In addition, pressure loss and the consumption of steel plate are considered. A flow model test (FMT) is carried out to verify the CFD simulation results. This may provide an effective approach to optimize the tower type SCR-deNO ${ }_{x}$ facilities.

\section{CFD Simulation and FMT Validation}

\subsection{Facility Optimization}

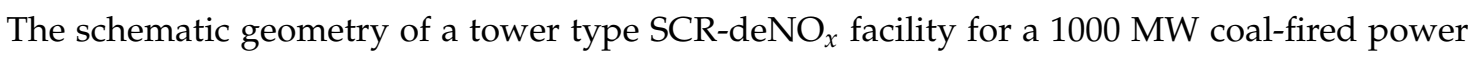
plant is shown in Figure 1. The power plant is located in Tuandong Town, Neixiang County, Nanyang City, Henan Province of China. It belongs to the State Development and Investment Corp. The overall height of the SCR-deNO $\mathrm{O}_{x}$ facility is about $100 \mathrm{~m}$ and the flow rate of the flue gas is about $1030 \mathrm{~kg} / \mathrm{s}$ with a temperature of $647.15 \mathrm{~K}$ under $100 \%$ BMCR condition. The flue gas inlet size is about $21 \mathrm{~m} \times 6 \mathrm{~m}$ and the sectional area of the catalyst layer is approximately $430 \mathrm{~m}^{2}$.

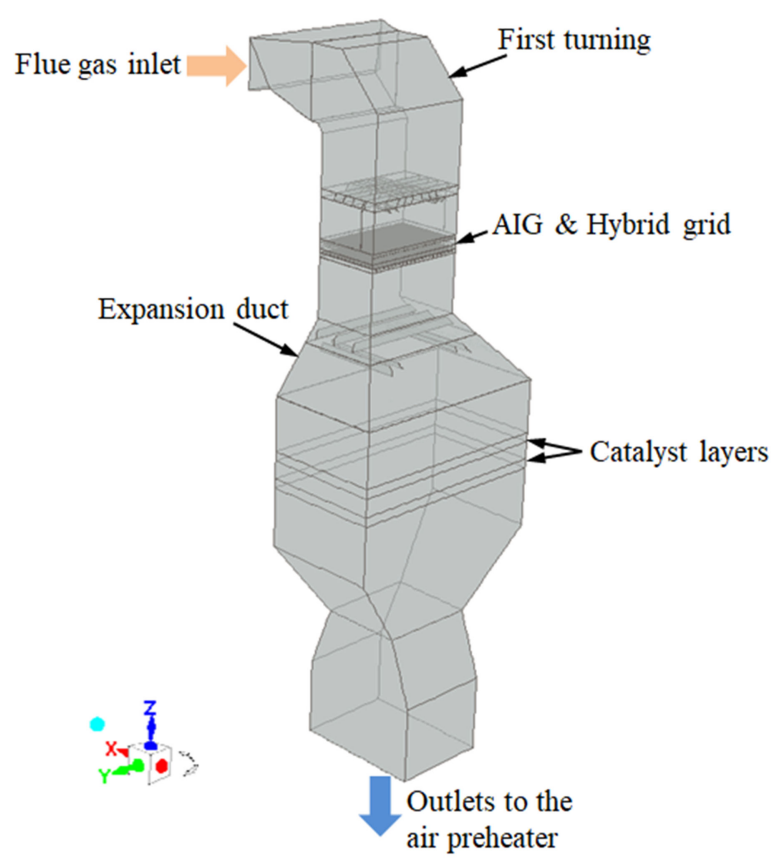

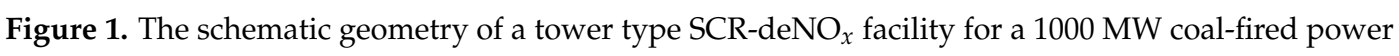
plant. AIG: Ammonia Injection Grid. 
The flue gas leaves the economizer and passes the first turning. Then it mixes with $\mathrm{NH}_{3}$ that is injected by the AIG. After that, the flue gas goes through the hybrid grid and the expansion duct. Finally, it enters the SCR reactors, which contain two catalyst layers. The mixing distance for flue gas and $\mathrm{NH}_{3}$ is approximately $25 \mathrm{~m}$ from the AIG to the catalyst entrance.

The relative standard deviation (RSD) at the entrance of catalyst layers is used to evaluate the uniformity of both gas velocity and $\mathrm{NH}_{3}$ concentration distribution, which is defined as [24,25]:

$$
\mathrm{RSD}=\frac{\sqrt{\sum_{i=1}^{n}\left(x_{i}-\bar{x}\right)^{2}}}{(n-1)^{1 / 2} \cdot \bar{x}}
$$

where $x_{i}$ is the $i$-th measured value of the variable, $\bar{x}$ is its average value, and $n$ is the total sampling number. Usually, the RSD is set to less than $15 \%$ for the flue gas velocity distribution and less than $5 \%$ for the $\mathrm{NH}_{3}$ concentration distribution. In the facility design stage, pressure loss is also a very important issue because it is directly related to energy consumption. Correspondingly, a total pressure loss of less than $400 \mathrm{~Pa}$ is required excluding the catalysts' pressure loss. In addition, with the promotion of China's high-quality development, the consumption of steel plate also needs to be considered.

For this tower type SCR-deNO $\mathrm{N}_{x}$ facility, optimal design is required with spatial constraints. No baffles are allowed to be installed inside the first turning because it is too close to the economizer. Therefore, it is more difficult to achieve the requirements of RSD mentioned previously and to control the pressure loss. A variety of regulation measures should be taken during the design stage of the

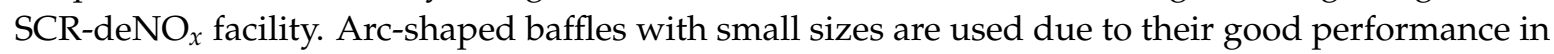
regulating the flow field while reducing the total pressure loss.

Meanwhile, attempts also are made to regulate the flow field at the AIG as a potential solution to spatial constraints. Installing the baffles at the upstream side of the facility would reduce the difficulty in regulating the downstream flow field, especially for the expansion duct.

Correspondingly, a non-uniformed $\mathrm{NH}_{3}$ injection strategy was adopted to increase the uniformity of $\mathrm{NH}_{3}$ concentration distribution. Considering the large sectional area and insufficient turbulence, it was necessary to use the non-uniformity $\mathrm{NH}_{3}$ injection strategy to enhance the mixing performance. In this case, the AIG had 21 independent $\mathrm{NH}_{3}$ injection areas $(3 \times 7)$ and the $\mathrm{NH}_{3}$ injection velocity of each area was set to be proportional to the gas velocity based on the gas velocity distribution before the AIG. With the flow field regulated at the AIG, it was much easier to determine the injection velocities.

The optimization process was carried out based on CFD simulation and FMT validation. Firstly, the CFD simulation of the tower type SCR-deNO $\mathrm{S}_{x}$ facility with no baffles geometry was performed as an indication of the flow field. Secondly, on the basis of the preliminary simulation, the baffles geometry was designed. The RSDs of gas velocity and $\mathrm{NH}_{3}$ concentration, as well as the pressure loss were calculated. Adjustments were made on the configuration of the baffles until the RSDs and the total pressure loss performed as low as possible. In addition, the consumption of steel plate was calculated and considered. Finally, FMT was conducted as a validation of the CFD simulations.

\subsection{CFD Simulation}

Three-dimensional CFD simulation was carried out with ANSYS 17.1, ANSYS Inc. [26]. The meshing model was established with the real scale. The total mesh number of the geometry was about 5.9 million. Due to the limitation of the hardware, the grid convergence analysis was only carried out on the meshing geometry of the AIG and the hybrid grid. The corresponding results are shown in Appendix A. Figure 2 shows the meshing geometry of the representative area.

The model is considered to be adiabatic and the chemical reactions are not considered here. A standard $k-\varepsilon$ model was used to deal with the turbulence and a SIMPLE (Semi-Implicit Method for Pressure-Linked Equation) algorithm was used to solve the Navier-Stokes equation. Moreover, a porous media model was used as a substitute for catalyst layers and the permeability term was 
eliminated considering the honeycomb structure of the catalyst layers. The corresponding boundary conditions are given below:

(1) The flow distribution of inlet was set to be uniform as the sufficient resistance provided by the economizer. The velocity was $14.75 \mathrm{~m} / \mathrm{s}$ under $100 \%$ BMCR condition;

(2) The $\mathrm{NH}_{3}$ concentration was diluted to $5 \%$ and the corresponding average injection velocity was set to $20 \mathrm{~m} / \mathrm{s}$ based on the $\mathrm{NH}_{3} / \mathrm{NO}_{x}$ molar ratio of 1:1;

(3) An atmospheric pressure was set at the pressure outlet and the total pressure loss of two catalyst layers was set to $420 \mathrm{~Pa}$;

(4) An observation plane was located $0.2 \mathrm{~m}$ above the porous media. As the overall height of the tower type SCR-deNO ${ }_{x}$ facility is about $100 \mathrm{~m}$, the flue gas velocity and $\mathrm{NH}_{3}$ concentration distributions at the observation plane can be regarded as those of the catalyst entrance.

Iteration continued until the residuals had converged below $10^{-6}$. Contours of gas velocity and $\mathrm{NH}_{3}$ concentration at the observation plane were generated respectively. Thereafter, the corresponding RSDs and the total pressure loss were calculated.

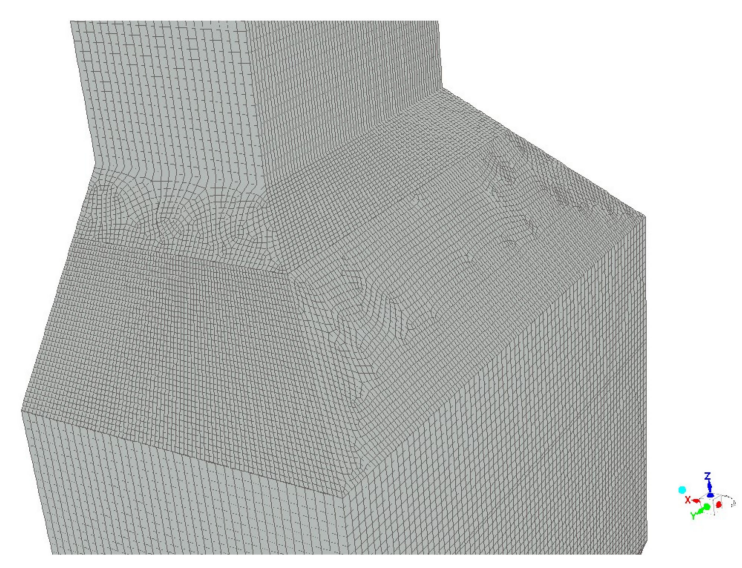

Figure 2. Meshing geometry of the representative area.

\subsection{FMT Validation}

A flow model test was constructed to verify the CFD simulation results. Figure 3 indicates the platform of FMT experiments.

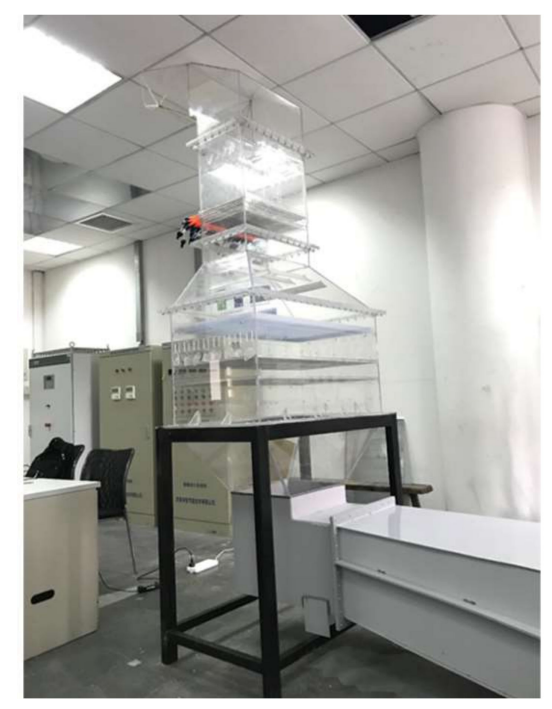

Figure 3. The platform of flow model test (FMT) experiments. 
The model of the tower type SCR-deNO $\mathrm{N}_{x}$ facility was made of transparent plexiglas with a scale of 1:30. A perforated plate was used to represent the pressure drop of the catalyst layers. Slices made of aluminum were used as the baffles, AIG, hybrid grid, and straightener. During the experiments, chemical reactions were neglected. Air and carbon dioxide $\left(\mathrm{CO}_{2}\right)$ were substituted for flue gas and $\mathrm{NH}_{3}$. A Testo- 445 multi-function measuring instrument with different probes was used to measure the variables. A vane probe was used to measure the air velocity. Its measuring range is 0.6 to $40 \mathrm{~m} / \mathrm{s}$ with a resolution of $0.01 \mathrm{~m} / \mathrm{s}$. The corresponding accuracy is $\pm(0.2 \mathrm{~m} / \mathrm{s} \pm 1.5 \%$ of measurement value $)$ ( +0.6 to $+40 \mathrm{~m} / \mathrm{s})$. A $\mathrm{AO}_{2}$ probe was used to measure the $\mathrm{CO}_{2}$ concentration. Its measuring range is 0 to $10,000 \mathrm{ppm}$ with a resolution of $1 \mathrm{ppm}$. The corresponding accuracy is $\pm(500 \mathrm{ppm}+2 \%$ of measurement value) $(0$ to $+5000 \mathrm{ppm})$ and $\pm(100 \mathrm{ppm}+3 \%$ of measurement value) $(+5000$ to $+10,000)$. In addition, a pressure probe was used to measure the pressure loss. Its measuring range is 0 to $100 \mathrm{hPa}$ with the resolution of $0.01 \mathrm{hPa}$. The corresponding accuracy is $\pm 0.1 \mathrm{hPa}(0$ to $+20 \mathrm{hPa})$ and $\pm 0.5 \%$ of measurement value $(+20$ to $+100 \mathrm{hPa})$. Figure 4 indicates the 64 detection spots that are arranged as an $8 \times 8$ matrix over the perforated plate.

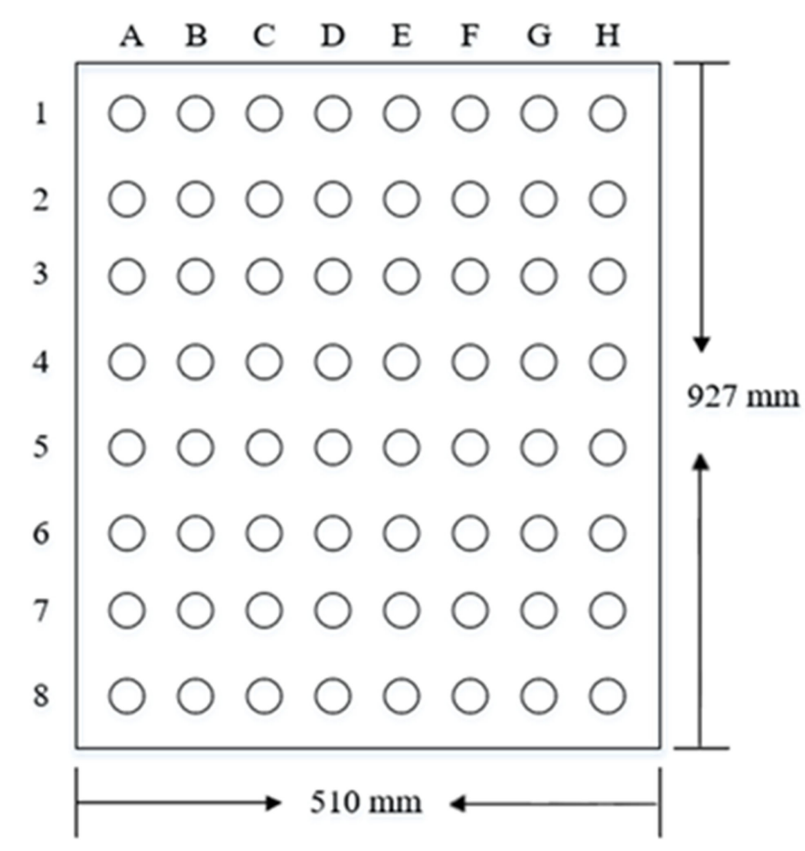

Figure 4. The sketch map of detection spots over the perforate plate.

The experiments were repeated five times at room temperature while the air inlet velocities were modified to close to $14.75 \mathrm{~m} / \mathrm{s}$, which is in accordance with the case of $100 \%$ BMCR condition. The experimental results are shown in Appendix $\mathrm{B}$. The average values of air velocity, $\mathrm{CO}_{2}$ concentration, and pressure loss were calculated and recorded. Comparisons are presented between the results of the FMT experiments and CFD simulations as a validation of the optimal design.

\section{Results and Discussion}

After optimization, baffles were installed in the expansion duct. The corresponding configuration is shown in Figure 5. The specific sizes and locations of the baffles are shown in Figure 6.

A group of crossed baffles were installed before the AIG. The corresponding configuration is shown in Figure 7. Figure 8 illustrates the specific sizes and locations of the baffles. The consumption of the $6 \mathrm{~mm}$ steel plate was about $1.13 \mathrm{~m}^{3}$ and the corresponding surface area of the baffles was about $188 \mathrm{~m}^{2}$, which is quite small compared with the sectional area of the catalyst layer of $430 \mathrm{~m}^{2}$.

Figure 9 shows the contours of gas velocity at the observation plane for the optimal design. According to Figure 9, the RSD of gas velocity is $11.90 \%$ and the maximum velocity is $6.64 \mathrm{~m} / \mathrm{s}$. 
Figure 10a gives the injection divisions of AIG and Figure 10b gives the corresponding non-uniformed $\mathrm{NH}_{3}$ injection strategy. Figure 11 shows the contours of $\mathrm{NH}_{3}$ concentration with the non-uniformed $\mathrm{NH}_{3}$ injection strategy applied. The $\mathrm{RSD}$ of $\mathrm{NH}_{3}$ concentration is $3.37 \%$ and the range varies from $1.53 \times 10^{-3}$ to $1.86 \times 10^{-3} \mathrm{~kg} / \mathrm{m}^{3}$, indicating that the flue gas and the $\mathrm{NH}_{3}$ are mixed adequately.

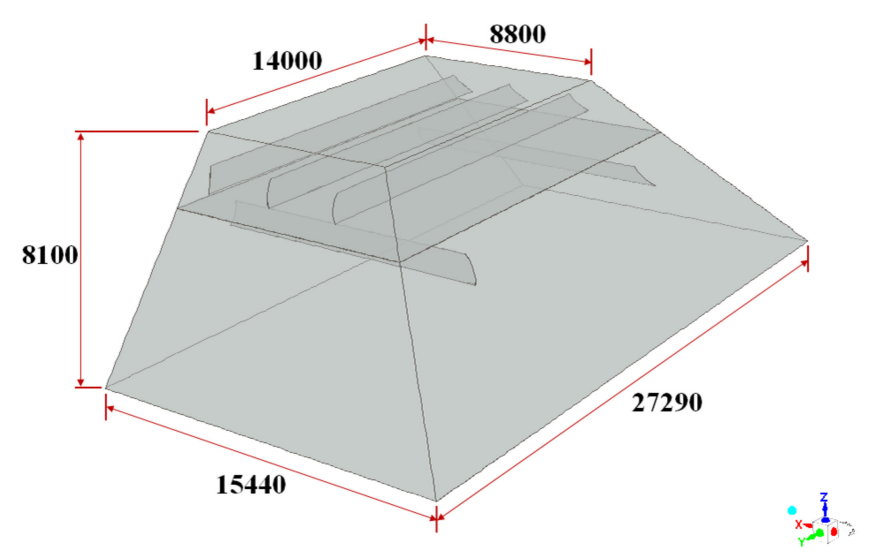

Figure 5. The baffles installation in the expansion duct for the optimal design (unit: $\mathrm{mm}$ ).

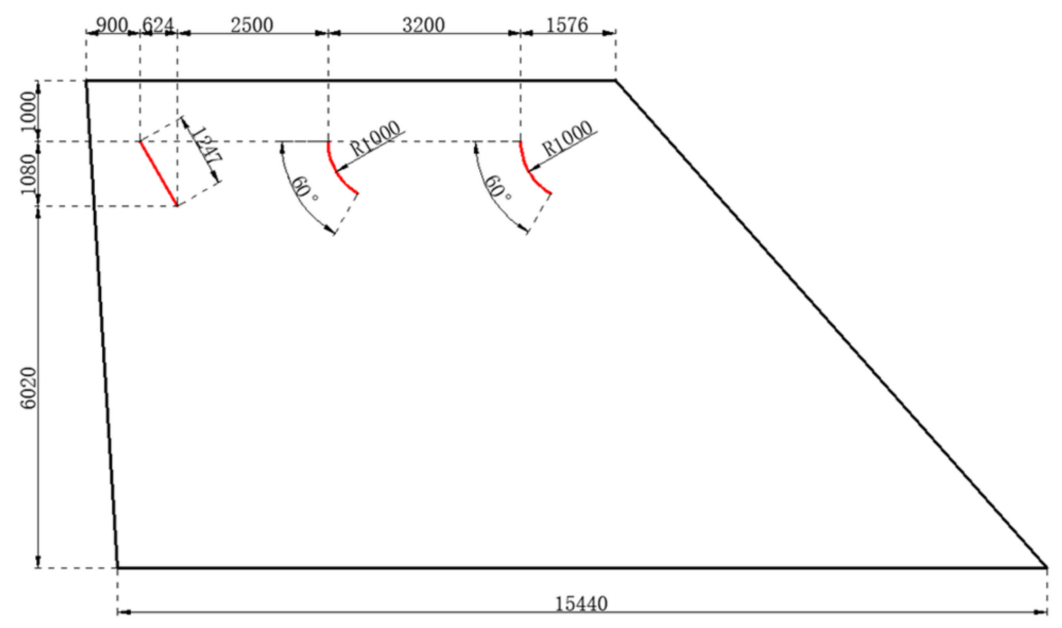

(a)

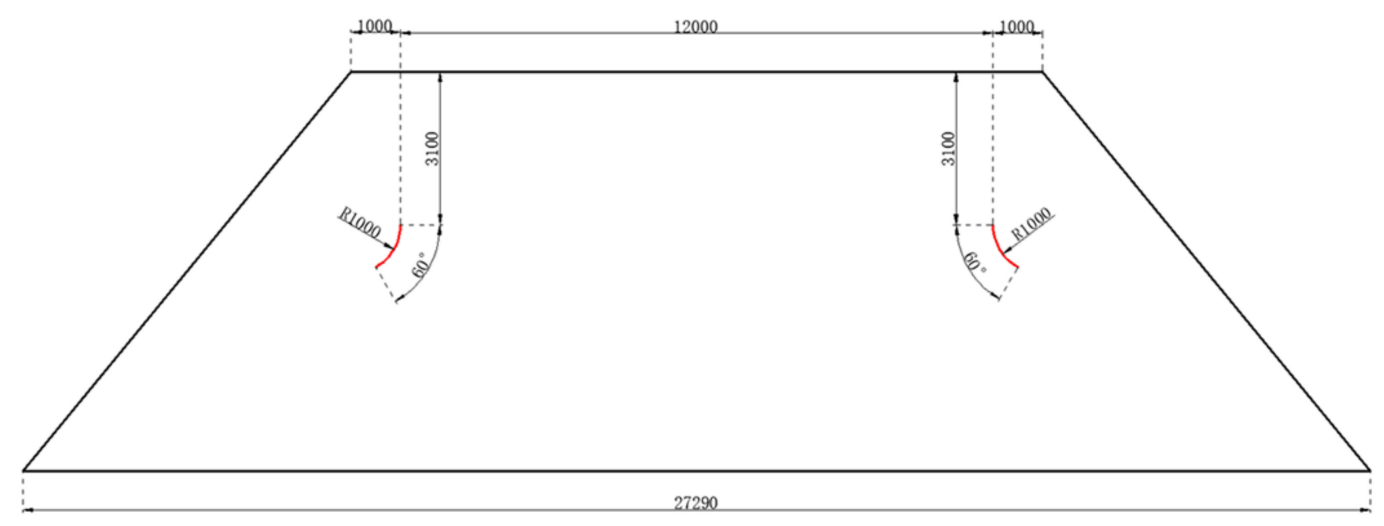

(b)

Figure 6. The sizes and locations of the baffles installation in the expansion duct: (a) Y-positive view; (b) X-negative view. 


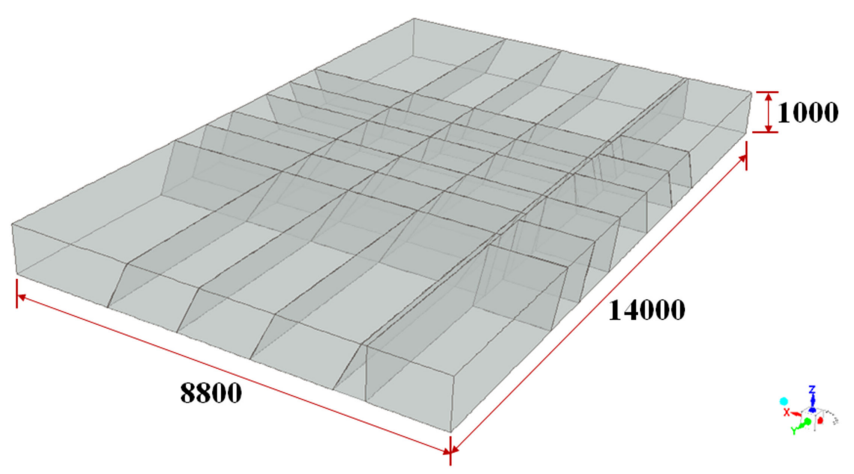

Figure 7. The crossed baffles installation at the upstream side of the ammonia injection grid (AIG) (unit: $\mathrm{mm}$ ).

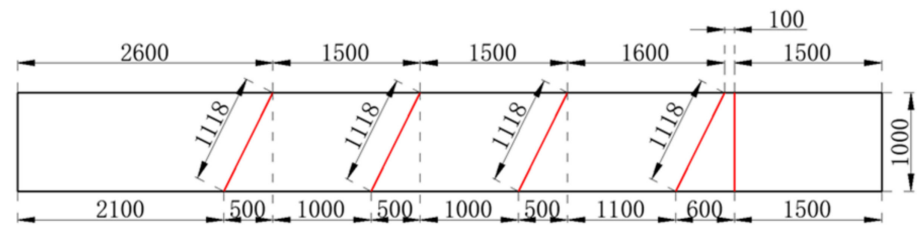

(a)

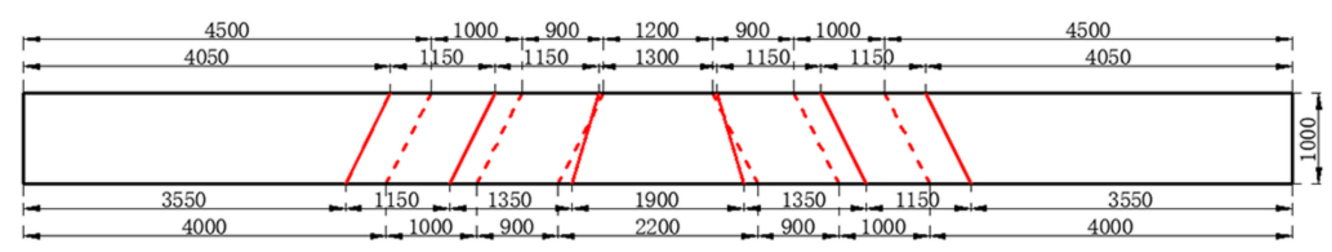

(b)

Figure 8. The sizes and locations of the crossed baffles installation at the upstream side of the AIG: (a) Y-positive view; (b) X-negative view.
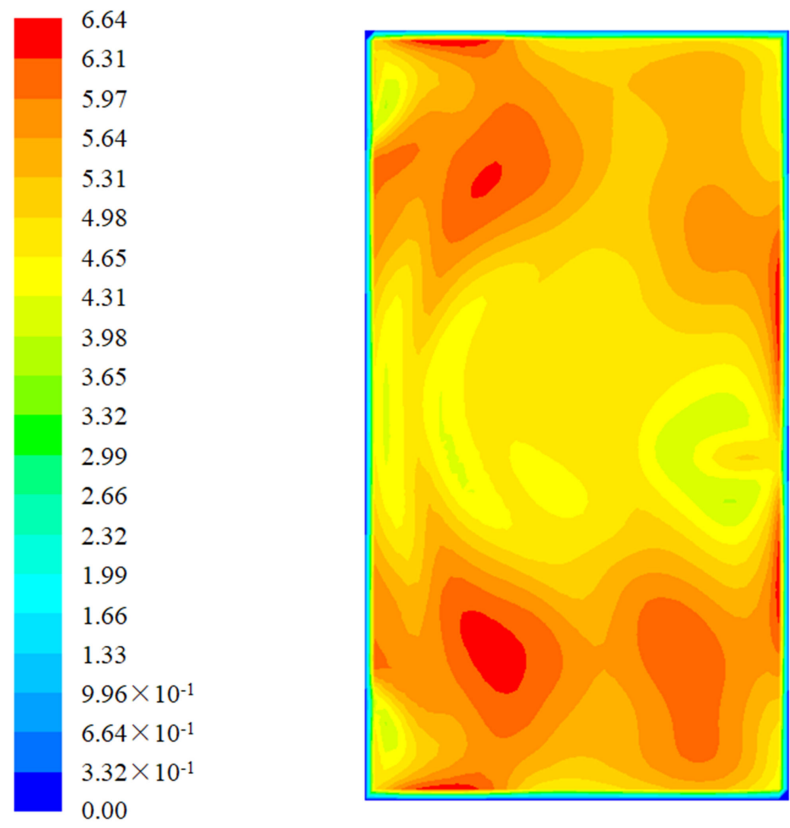

Figure 9. Contours of gas velocity at the observation plane for the optimal design (unit: $\mathrm{m} / \mathrm{s}$ ). 


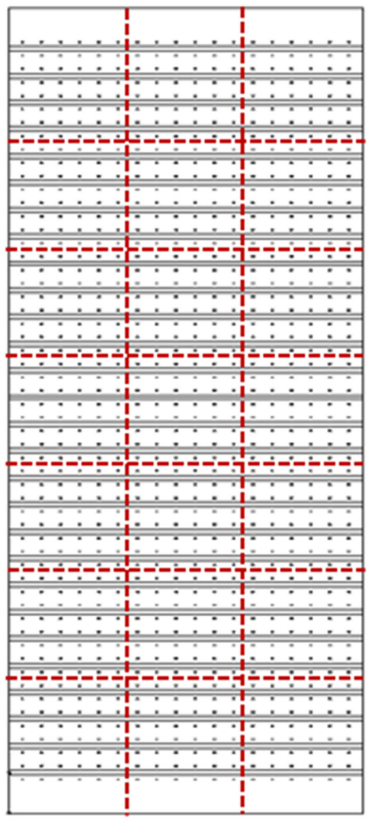

\begin{tabular}{|c|c|c|}
\hline 24 & 21 & 20 \\
\hline 21 & 23 & 24 \\
\hline 10 & 14 & 22 \\
\hline 20 & 18 & 21 \\
\hline 20 & 15 & 21 \\
\hline 17 & 21 & 22 \\
\hline 24 & 23 & 19 \\
\hline
\end{tabular}

Figure 10. (a) The injection divisions of AIG (top view); (b) The corresponding non-uniformed $\mathrm{NH}_{3}$ injection strategy (unit: $\mathrm{m} / \mathrm{s}$ ).
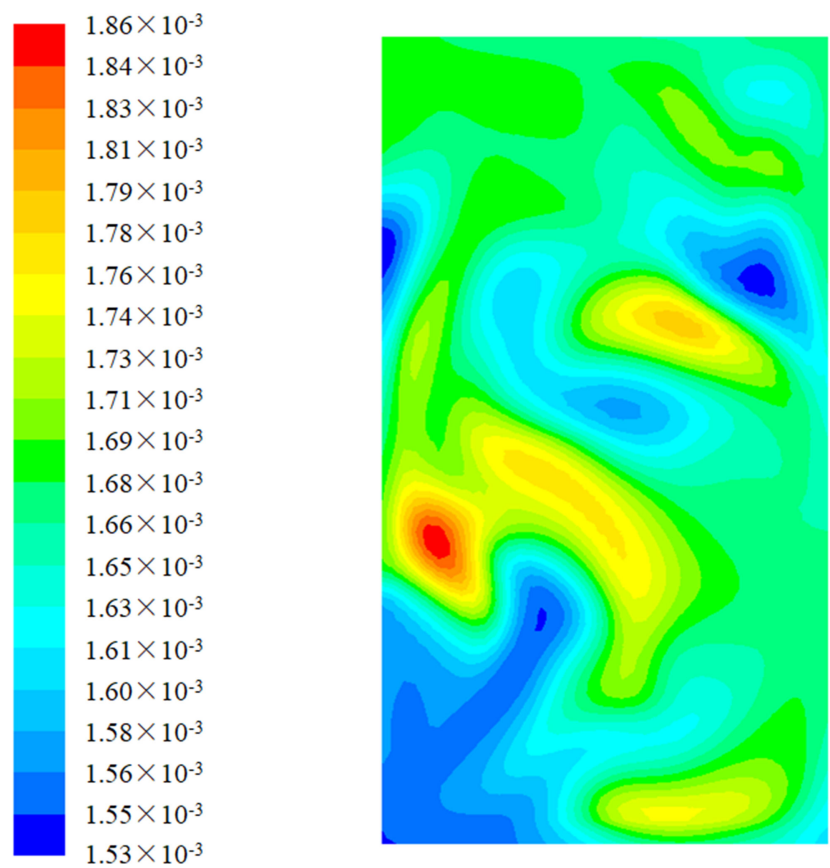

Figure 11. Contours of $\mathrm{NH}_{3}$ concentration at the observation plane for the optimal design (unit: $\mathrm{kg} / \mathrm{m}^{3}$ ).

Comparisons were made to evaluate the effect of the crossed baffles. Figure 12 illustrates the influence of the crossed baffles on gas velocities and $\mathrm{NH}_{3}$ concentration. After installing the crossed baffles shown in Figures 7 and 8, the RSDs of gas velocity and $\mathrm{NH}_{3}$ concentration decreased by $18.2 \%$ and $25.6 \%$, respectively. It is revealed that the crossed baffles are helpful in regulating the flow field. Moreover, when optimizing the tower type SCR-deNO $\mathrm{N}_{x}$ facility with spatial constraints, regulating the flow field at the AIG may provide an effective way to achieve a more homogeneous distribution at the entrance of catalyst layers. 
In addition, in order to control pressure loss, all of the small-sized baffles were installed at the upstream side of the facility. Simulation results showed that the total pressure loss for the optimal design was $330.61 \mathrm{~Pa}$, which is less than the requirement of $400 \mathrm{~Pa}$.

Table 1 summarizes the statistic indices of the tower type SCR-deNO $\mathrm{S}_{x}$ facility before and after the optimal design. According to Table 1, the RSDs of gas velocity and $\mathrm{NH}_{3}$ concentration decreased by 18.30 and 5.50 percentage points, respectively. It is indicated that the flow field inside the SCR facility is regulated remarkably after the optimal design. The maximum velocity at the observation plane decreased by $6.83 \mathrm{~m} / \mathrm{s}$, which would greatly reduce the risk of catalyst breakage. Additionally, the existence of the optimal baffles provides an extra pressure loss of 195.44 Pa.

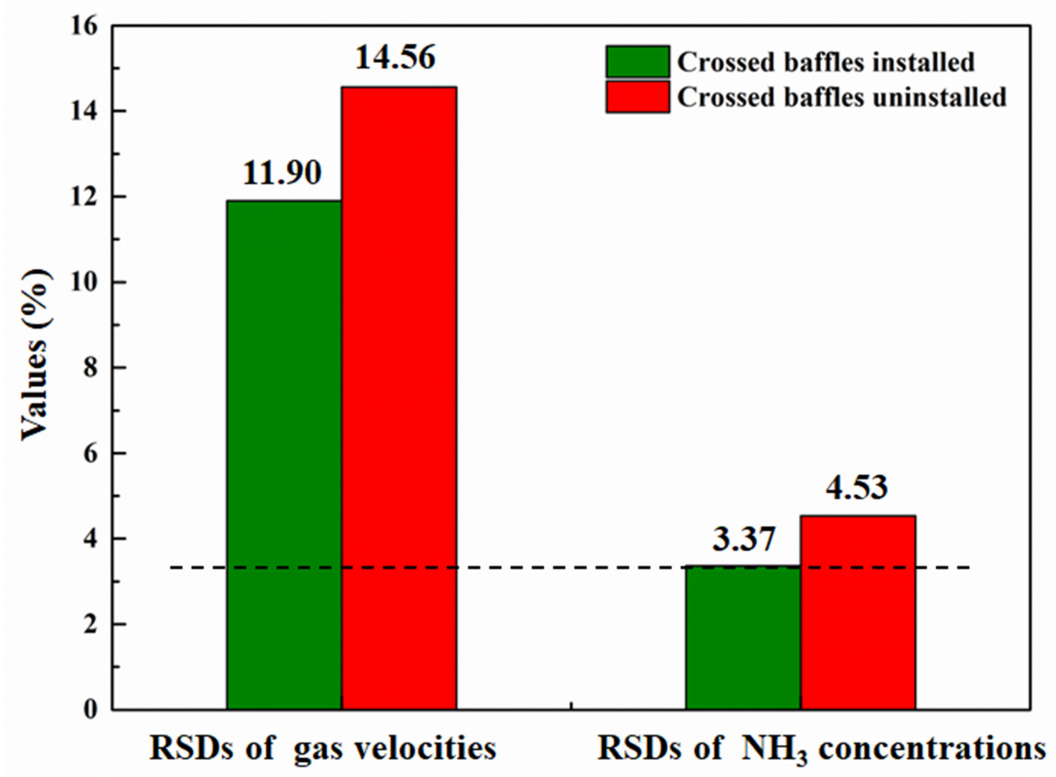

Figure 12. The influence of the crossed baffles on gas velocities and $\mathrm{NH}_{3}$ concentration.

Table 1. Comparisons between the statistic indices before and after the optimal design.

\begin{tabular}{lcc}
\hline \multicolumn{1}{c}{ Item } & Before the Optimal Design & After the Optimal Design \\
\hline Maximum velocity $(\mathrm{m} / \mathrm{s})$ & 13.47 & 6.64 \\
RSD of gas / air velocity $(\%)$ & 30.20 & 11.90 \\
RSD of $\mathrm{NH}_{3} / \mathrm{CO}_{2}$ concentration $(\%)$ & 9.25 & 3.37 \\
Total pressure loss (Pa) & 555.17 & 750.61 \\
Pressure loss (catalysts excluded, $\mathrm{Pa})$ & 135.17 & 330.61 \\
\hline
\end{tabular}

Tables 2 and 3 show the measured values of air velocity and $\mathrm{CO}_{2}$ concentration for the FMT experiments. According to Table 2, the RSD of air velocity is $11.24 \%$ and the maximum velocity is $4.76 \mathrm{~m} / \mathrm{s}$. FMT results show that the lower velocity areas are located in the upper edge and the bottom edge. Meanwhile, the air flow runs faster at the left half (A-D) of the plane. Table 3 gives a decent concentration distribution. The RSD of $\mathrm{CO}_{2}$ concentration is $4.98 \%$. 
Table 2. FMT results of air velocity distribution $(\mathrm{m} / \mathrm{s})$.

\begin{tabular}{ccccccccc}
\hline & A & B & C & D & E & F & G & H \\
\hline 1 & 3.26 & 3.58 & 3.58 & 3.56 & 3.12 & 3.25 & 3.53 & 3.23 \\
2 & 4.07 & 4.24 & 4.54 & 4.41 & 4.18 & 4.30 & 4.67 & 3.99 \\
3 & 4.60 & 4.62 & 4.62 & 4.23 & 4.62 & 3.94 & 4.33 & 4.54 \\
4 & 4.35 & 4.40 & 4.58 & 4.36 & 4.08 & 4.14 & 4.30 & 4.21 \\
5 & 4.07 & 4.58 & 4.76 & 4.27 & 4.61 & 4.47 & 4.62 & 4.40 \\
6 & 4.29 & 4.54 & 4.32 & 4.50 & 4.50 & 4.16 & 4.51 & 4.26 \\
7 & 4.24 & 4.13 & 4.34 & 4.42 & 4.45 & 4.17 & 3.76 & 3.88 \\
8 & 3.31 & 3.81 & 3.56 & 3.37 & 3.22 & 3.19 & 3.73 & 3.29 \\
\hline
\end{tabular}

Table 3. FMT results of $\mathrm{CO}_{2}$ concentration distribution (ppm).

\begin{tabular}{ccccccccc}
\hline & A & B & C & D & E & F & G & H \\
\hline 1 & 2055 & 2031 & 2183 & 2170 & 1997 & 2180 & 1918 & 2192 \\
2 & 2169 & 1836 & 2057 & 2030 & 2039 & 2052 & 2010 & 2081 \\
3 & 2127 & 1918 & 2196 & 2182 & 1959 & 2052 & 1991 & 2144 \\
4 & 2181 & 1937 & 2074 & 2028 & 2068 & 1949 & 1903 & 2108 \\
5 & 2106 & 1849 & 2129 & 1835 & 2165 & 2140 & 2106 & 2168 \\
6 & 1842 & 2089 & 2167 & 2021 & 2018 & 1921 & 1961 & 2096 \\
7 & 2144 & 2040 & 2031 & 1940 & 2138 & 1951 & 1870 & 2096 \\
8 & 2133 & 2072 & 2027 & 2175 & 2130 & 2008 & 1938 & 1933 \\
\hline
\end{tabular}

Comparisons are made between the results of CFD simulations and FMT experiments. Table 4 shows the corresponding statistic indices. According to Table 4, both the CFD simulations and FMT experiments achieve the design requirements and perform homogeneous distributions of velocity and concentration. Most of the statistic indices between CFD simulations and FMT experiments are at the same level. For the gas/air velocity distributions, the RSDs are quite close and the difference is only 0.66 percentage points. The deviations of velocities and concentrations may be attributed to detection accuracy and installation accuracy. For instance, the detection spots are unable to cover the whole plane in the FMT and deviations may appear between the actual installation and the optimal design of baffles geometry. For total pressure loss, Table 4 shows a relatively large deviation of $79.61 \mathrm{~Pa}$. It is plausible to treat this as a result of the deviations of velocities. From Figures 9 and 11 and Tables 2 and 3, it is indicated that the distribution tendencies of gas/air velocity and $\mathrm{NH}_{3} / \mathrm{CO}_{2}$ concentration are similar.

Table 4. Comparisons between computational fluid dynamics (CFD) simulations and FMT experiments.

\begin{tabular}{lcc}
\hline \multicolumn{1}{c}{ Item } & CFD & FMT \\
\hline Maximum velocity (m/s) & 6.64 & 4.76 \\
Minimum velocity (m/s) & 3.72 & 3.12 \\
Average velocity (m/s) & 5.45 & 4.11 \\
RSD of gas/air velocity (\%) & 11.90 & 11.24 \\
RSD of NH3/CO2 concentration (\%) & 3.37 & 4.98 \\
Total pressure loss (Pa) & 750.61 & 640 \\
Pressure loss (catalysts excluded, Pa) & 330.61 & 251 \\
\hline
\end{tabular}

In general, it is revealed that the FMT results are basically consistent with the CFD results, indicating that the optimal design is effective for the tower type $\mathrm{SCR}-\mathrm{deNO} x$ facility with spatial constraints.

The tower type SCR-deNO ${ }_{x}$ facility is quite different from the traditional $\pi$ type one. To implement the flow regulation, it is recommended to use small-sized baffles and to install the baffles geometry at the upstream side of the facility. It has the advantages of controlling the pressure loss and the consumption of steel plate. Furthermore, regulating the flow field at the AIG is proven to be an effective way to deal with spatial constraints. It can be applied to SCR-deNO $\mathrm{N}_{x}$ facilities that have compact 
configurations such as reconstructed facilities. Additionally, it helps to determine the non-uniformed $\mathrm{NH}_{3}$ injection strategy and to achieve a more homogeneous distribution of gas velocity and $\mathrm{NH}_{3}$ concentration. This paper presents not only the configuration of the baffles geometry but also many specific indices and details during the optimization. It can provide a good reference for optimizing the tower type SCR-deNO $\mathrm{S}_{x}$ facility.

\section{Conclusions}

In this study, the flow field of the tower type SCR-deNO $x$ facility for a $1000 \mathrm{MW}$ coal-fired power plant is optimized and presented. Baffles geometry and the non-uniformed ammonia injection strategy are performed via computational fluid dynamics. According to the real operation condition, the corresponding relative standard deviations of gas velocity and ammonia concentration are $11.90 \%$ and 3.37\%, respectively. All statistical indices achieve the design requirements. Furthermore, a flow model test is carried out to validate the computational fluid dynamics-based optimal design, where air and $\mathrm{CO}_{2}$ are substituted for flue gas and ammonia. The corresponding relative standard deviations are $11.24 \%$ and $4.98 \%$. Both the computational fluid dynamics and flow model test show that the uniformity of the flow field is greatly improved by the optimal design and the flow model test experimental data are consistent with the computational fluid dynamics simulation results. For the tower type SCR-deNO ${ }_{x}$ facility, small-sized baffles are recommended to be installed at the upstream side of the facility. This has the advantages of improving the uniformity of flow field and controlling the pressure loss and the consumption of steel plate. Furthermore, regulating the flow field at the ammonia injection grid is proven to be an effective way to deal with spatial constraints. The optimal design may be valuable for further study on flow field regulation of tower type SCR-deNO $\mathrm{N}_{x}$ facilities with spatial constraints.

Author Contributions: Conceptualization, H.Z.; Data curation, H.Z.; Formal analysis, H.Z.; Funding acquisition, J.Y.; Investigation, H.Z.; Methodology, H.Z. and J.Y.; Project administration, J.Y.; Resources, J.Y.; Supervision, J.Y.; Validation, H.Z. and J.W.; Writing-original draft, H.Z.; Writing-review \& editing, J.Y.

Funding: This research was funded by the National Natural Science Foundation of China, grant number 61533013 and the Natural Science Foundation of Shanghai, grant number 17ZR1414200.

Conflicts of Interest: The authors declare no conflict of interest.

\section{Abbreviations}

$\begin{array}{ll}\text { AIG } & \text { Ammonia Injection Grid } \\ \text { BMCR } & \text { Boiler Maximum Continuous Rating } \\ \text { CFD } & \text { Computational Fluid Dynamics } \\ \text { FMT } & \text { Flow Model Test } \\ \text { RSD } & \text { Relative Standard Deviation } \\ \text { SCR } & \text { Selective Catalytic Reduction }\end{array}$

\section{Appendix A}

In the following, the grid convergence analysis is presented. Due to limitations in the hardware, the grid convergence analysis is only carried out on the most complex part of the meshing geometry, which is the AIG and the hybrid grid. The sizes of the grid are chosen to be $100 \mathrm{~mm}, 60 \mathrm{~mm}, 50 \mathrm{~mm}$, and $40 \mathrm{~mm}$. The corresponding number of nodes are about 0.45 million, 0.84 million, 1.36 million, and 2.48 million, respectively. The relative standard deviations of velocity are calculated to indicate the performance. The results show that the corresponding relative standard deviations are $9.7 \%, 7.1 \%, 6.2 \%$, and $6.0 \%$. It is revealed that the $50 \mathrm{~mm}$ grid is appropriate to be chosen as the smallest size for the meshing geometry.

\section{Appendix B}

In the following, five experimental results of FMT are provided. For each experiment, the measured values of air velocity, $\mathrm{CO}_{2}$ concentration, and pressure loss are recorded and presented in tables.

Experiment A1. The air inlet velocity is $14.24 \mathrm{~m} / \mathrm{s}$. 
Table A1. Measured values of air velocity distribution in Experiment A1 (m/s).

\begin{tabular}{ccccccccc}
\hline & A & B & C & D & E & F & G & H \\
\hline 1 & 3.45 & 3.62 & 3.24 & 3.47 & 2.89 & 3.02 & 3.07 & 2.76 \\
2 & 4.32 & 3.79 & 4.83 & 4.14 & 3.16 & 3.58 & 4.29 & 3.78 \\
3 & 5.44 & 3.89 & 4.91 & 4.74 & 4.04 & 3.17 & 4.93 & 4.95 \\
4 & 4.13 & 4.41 & 4.11 & 4.23 & 3.58 & 3.41 & 4.06 & 3.94 \\
5 & 3.38 & 4.88 & 5.44 & 4.22 & 4.54 & 4.06 & 5.16 & 4.32 \\
6 & 3.79 & 4.67 & 4.16 & 4.43 & 4.21 & 3.79 & 4.85 & 4.03 \\
7 & 3.64 & 3.84 & 4.44 & 4.75 & 4.89 & 3.82 & 3.03 & 3.58 \\
8 & 3.40 & 4.30 & 3.16 & 2.91 & 2.31 & 2.46 & 3.09 & 2.67 \\
\hline
\end{tabular}

Table A2. Measured values of $\mathrm{CO}_{2}$ concentration distribution in Experiment A1 (ppm).

\begin{tabular}{ccccccccc}
\hline & A & B & C & D & E & F & G & H \\
\hline 1 & 2475 & 2371 & 2574 & 2513 & 2385 & 2411 & 2168 & 2555 \\
2 & 2452 & 2081 & 2346 & 2392 & 2372 & 2449 & 2420 & 2453 \\
3 & 2476 & 2335 & 2575 & 2431 & 2422 & 2506 & 2449 & 2604 \\
4 & 2431 & 2413 & 2325 & 2490 & 2505 & 2414 & 2369 & 2706 \\
5 & 2535 & 2352 & 2274 & 2169 & 2465 & 2555 & 2419 & 2430 \\
6 & 2105 & 2504 & 2581 & 2227 & 2419 & 2206 & 2307 & 2294 \\
7 & 2482 & 2490 & 2345 & 2334 & 2450 & 2362 & 2228 & 2369 \\
8 & 2408 & 2459 & 2519 & 2542 & 2424 & 2396 & 2378 & 2370 \\
\hline
\end{tabular}

Table A3. Pressure loss in Experiment A1 (Pa).

\begin{tabular}{lc}
\hline \multicolumn{1}{c}{ Item } & Measurement Value \\
\hline $\begin{array}{l}\text { Total pressure loss } \\
\text { Pressure loss (catalysts } \\
\text { excluded) }\end{array}$ & 627 \\
\hline
\end{tabular}

Experiment A2. The air inlet velocity is $14.66 \mathrm{~m} / \mathrm{s}$.

Table A4. Measured values of air velocity distribution in Experiment A2 (m/s).

\begin{tabular}{ccccccccc}
\hline & A & B & C & D & E & F & G & H \\
\hline 1 & 3.37 & 3.13 & 3.06 & 2.51 & 2.37 & 3.09 & 3.16 & 2.78 \\
2 & 4.31 & 3.85 & 4.33 & 4.45 & 4.55 & 4.65 & 4.74 & 3.48 \\
3 & 4.92 & 4.45 & 4.63 & 4.35 & 4.73 & 4.07 & 4.09 & 4.60 \\
4 & 4.51 & 4.39 & 4.59 & 4.52 & 3.85 & 4.09 & 4.26 & 4.03 \\
5 & 3.93 & 4.80 & 5.05 & 4.19 & 4.65 & 4.51 & 4.59 & 4.41 \\
6 & 4.56 & 4.53 & 4.26 & 4.71 & 4.61 & 4.08 & 4.34 & 4.48 \\
7 & 3.70 & 4.11 & 4.31 & 4.53 & 4.38 & 4.32 & 3.59 & 4.08 \\
8 & 2.77 & 4.23 & 3.46 & 2.88 & 3.12 & 3.13 & 3.76 & 3.63 \\
\hline
\end{tabular}

Table A5. Measured values of $\mathrm{CO}_{2}$ concentration distribution in Experiment A2 (ppm).

\begin{tabular}{ccccccccc}
\hline & A & B & C & D & E & F & G & H \\
\hline 1 & 1956 & 2162 & 2255 & 2392 & 1803 & 2230 & 1997 & 2285 \\
2 & 2396 & 1747 & 2151 & 2118 & 2112 & 2082 & 2085 & 2224 \\
3 & 2210 & 2020 & 2361 & 2321 & 2033 & 2096 & 1921 & 2181 \\
4 & 2370 & 1869 & 2129 & 2054 & 2041 & 2102 & 1861 & 2154 \\
5 & 2027 & 1718 & 2213 & 1884 & 2263 & 2172 & 2245 & 2298 \\
6 & 1762 & 2091 & 2327 & 2141 & 2033 & 2138 & 2030 & 2210 \\
7 & 2179 & 1899 & 2131 & 1984 & 2321 & 1898 & 1923 & 2148 \\
8 & 2207 & 2116 & 1921 & 2372 & 2318 & 2108 & 2002 & 1930 \\
\hline
\end{tabular}


Table A6. Pressure loss in Experiment A2 (Pa).

\begin{tabular}{lc}
\hline \multicolumn{1}{c}{ Item } & Measurement value \\
\hline Total pressure loss & 636 \\
Pressure loss (catalysts excluded) & 251 \\
\hline
\end{tabular}

Experiment A3. The air inlet velocity is $14.77 \mathrm{~m} / \mathrm{s}$.

Table A7. Measured values of air velocity distribution in Experiment A3 (m/s).

\begin{tabular}{ccccccccc}
\hline & A & B & C & D & E & F & G & H \\
\hline 1 & 2.94 & 4.20 & 3.76 & 3.84 & 4.08 & 4.21 & 4.12 & 3.66 \\
2 & 3.34 & 4.32 & 4.52 & 4.42 & 4.52 & 4.42 & 4.56 & 4.76 \\
3 & 3.26 & 4.98 & 4.46 & 3.94 & 4.60 & 4.20 & 4.70 & 4.58 \\
4 & 3.92 & 4.42 & 4.48 & 4.18 & 4.36 & 4.10 & 4.26 & 4.42 \\
5 & 4.18 & 4.30 & 4.38 & 4.08 & 4.24 & 4.58 & 4.54 & 4.30 \\
6 & 4.18 & 4.06 & 4.16 & 4.16 & 4.50 & 4.19 & 4.72 & 4.00 \\
7 & 4.40 & 3.68 & 4.10 & 3.84 & 4.16 & 3.92 & 3.58 & 3.34 \\
8 & 3.86 & 3.26 & 4.02 & 3.66 & 3.20 & 3.32 & 3.74 & 2.98 \\
\hline
\end{tabular}

Table A8. Measured values of $\mathrm{CO}_{2}$ concentration distribution in Experiment A3 (ppm).

\begin{tabular}{ccccccccc}
\hline & A & B & C & D & E & F & G & H \\
\hline 1 & 2027 & 2018 & 2140 & 2127 & 1972 & 2093 & 1864 & 2117 \\
2 & 2084 & 1724 & 1985 & 1980 & 1992 & 1903 & 1940 & 2069 \\
3 & 2063 & 1821 & 2063 & 2211 & 1728 & 1976 & 1896 & 2106 \\
4 & 2045 & 1960 & 2030 & 1968 & 2015 & 1839 & 1839 & 2038 \\
5 & 2053 & 1790 & 2094 & 1776 & 2189 & 2097 & 2022 & 2158 \\
6 & 1832 & 2021 & 2097 & 1950 & 1932 & 1880 & 1921 & 2098 \\
7 & 2147 & 1940 & 1961 & 1806 & 2115 & 1843 & 1777 & 2028 \\
8 & 2115 & 1997 & 1895 & 2178 & 1997 & 1897 & 1799 & 1748 \\
\hline
\end{tabular}

Table A9. Pressure loss in Experiment A3 (Pa).

\begin{tabular}{lc}
\hline \multicolumn{1}{c}{ Item } & Measurement Value \\
\hline Total pressure loss & 640 \\
Pressure loss (catalysts excluded) & 250 \\
\hline
\end{tabular}

Experiment 4. The air inlet velocity is $14.83 \mathrm{~m} / \mathrm{s}$.

Table A10. Measured values of air velocity distribution in Experiment A4 (m/s).

\begin{tabular}{ccccccccc}
\hline & A & B & C & D & E & F & G & H \\
\hline 1 & 3.32 & 3.69 & 3.87 & 3.31 & 2.79 & 2.93 & 3.13 & 2.88 \\
2 & 4.13 & 4.45 & 4.75 & 4.49 & 4.25 & 4.35 & 4.91 & 3.57 \\
3 & 4.84 & 4.68 & 4.82 & 4.19 & 4.94 & 3.98 & 3.87 & 4.47 \\
4 & 4.62 & 4.29 & 4.70 & 4.24 & 3.97 & 4.15 & 4.34 & 4.32 \\
5 & 4.11 & 4.69 & 4.59 & 4.37 & 4.92 & 4.64 & 4.51 & 4.40 \\
6 & 4.39 & 4.31 & 4.19 & 4.71 & 4.54 & 4.19 & 4.53 & 4.32 \\
7 & 4.40 & 4.10 & 4.37 & 4.52 & 4.45 & 4.24 & 4.08 & 4.18 \\
8 & 3.15 & 4.16 & 3.32 & 3.06 & 3.15 & 3.22 & 3.83 & 2.87 \\
\hline
\end{tabular}


Table A11. Measured values of $\mathrm{CO}_{2}$ concentration distribution in Experiment A4 (ppm).

\begin{tabular}{ccccccccc}
\hline & A & B & C & D & E & F & G & H \\
\hline 1 & 2076 & 1833 & 2105 & 1982 & 1884 & 2162 & 1677 & 2192 \\
2 & 2200 & 1693 & 1993 & 1847 & 1965 & 1898 & 1879 & 1909 \\
3 & 2068 & 1656 & 2074 & 2185 & 1685 & 1905 & 1960 & 2051 \\
4 & 2158 & 1764 & 2117 & 1856 & 1899 & 1721 & 1716 & 1930 \\
5 & 1891 & 1631 & 2211 & 1624 & 2100 & 1936 & 2025 & 2090 \\
6 & 1634 & 1943 & 1982 & 1946 & 1890 & 1624 & 1649 & 1956 \\
7 & 2146 & 1760 & 1830 & 1673 & 1936 & 1664 & 1645 & 1961 \\
8 & 2055 & 1878 & 1887 & 1927 & 1917 & 1787 & 1679 & 1813 \\
\hline
\end{tabular}

Table A12. Pressure loss in Experiment A4 (Pa).

\begin{tabular}{lc}
\hline \multicolumn{1}{c}{ Item } & Measurement Value \\
\hline Total pressure loss & 641 \\
Pressure loss (catalysts excluded) & 251 \\
\hline
\end{tabular}

Experiment A5. The air inlet velocity is $15.07 \mathrm{~m} / \mathrm{s}$.

Table A13. Measured values of air velocity distribution in Experiment A5 (m/s).

\begin{tabular}{ccccccccc}
\hline & A & B & C & D & E & F & G & H \\
\hline 1 & 3.21 & 3.27 & 3.95 & 4.65 & 3.45 & 3.01 & 4.17 & 4.09 \\
2 & 4.27 & 4.79 & 4.27 & 4.57 & 4.43 & 4.52 & 4.87 & 4.37 \\
3 & 4.56 & 5.09 & 4.27 & 4.91 & 4.81 & 4.28 & 4.04 & 4.09 \\
4 & 4.56 & 4.49 & 5.00 & 4.65 & 4.63 & 4.95 & 4.60 & 4.32 \\
5 & 4.73 & 4.21 & 4.35 & 4.47 & 4.72 & 4.57 & 4.28 & 4.59 \\
6 & 4.55 & 5.13 & 4.81 & 4.51 & 4.63 & 4.53 & 4.12 & 4.48 \\
7 & 5.04 & 4.93 & 4.47 & 4.48 & 4.35 & 4.55 & 4.52 & 4.21 \\
8 & 3.36 & 3.09 & 3.84 & 4.33 & 4.32 & 3.80 & 4.25 & 4.29 \\
\hline
\end{tabular}

Table A14. Measured values of $\mathrm{CO}_{2}$ concentration distribution in Experiment A5 (ppm).

\begin{tabular}{ccccccccc}
\hline & A & B & C & D & E & F & G & H \\
\hline 1 & 1741 & 1771 & 1841 & 1836 & 1941 & 2004 & 1884 & 1811 \\
2 & 1713 & 1935 & 1810 & 1813 & 1754 & 1928 & 1726 & 1750 \\
3 & 1818 & 1758 & 1907 & 1762 & 1927 & 1777 & 1729 & 1778 \\
4 & 1901 & 1679 & 1769 & 1772 & 1880 & 1669 & 1730 & 1712 \\
5 & 2024 & 1754 & 1853 & 1722 & 1808 & 1940 & 1819 & 1864 \\
6 & 1877 & 1886 & 1848 & 1841 & 1816 & 1757 & 1898 & 1922 \\
7 & 1766 & 2111 & 1888 & 1903 & 1868 & 1988 & 1777 & 1974 \\
8 & 1880 & 1910 & 1913 & 1856 & 1994 & 1852 & 1832 & 1804 \\
\hline
\end{tabular}

Table A15. Pressure loss in Experiment A5 (Pa).

\begin{tabular}{lc}
\hline \multicolumn{1}{c}{ Item } & Measurement Value \\
\hline Total pressure loss & 657 \\
Pressure loss (catalysts excluded) & 258 \\
\hline
\end{tabular}

\section{References}

1. Skalska, K.; Miller, J.S.; Ledakowicz, S. Trends in $\mathrm{NO}_{x}$ abatement: A review. Sci. Total Environ. 2010, 408, 3976-3989. [CrossRef] [PubMed] 
2. Xiong, S.C.; Xiao, X.; Liao, Y.; Dang, H.; Shan, W.P.; Yang, S.J. Global Kinetic Study of NO Reduction by $\mathrm{NH}_{3}$ over $\mathrm{V}_{2} \mathrm{O}_{5}\left(\mathrm{WO}_{3}\right) / \mathrm{TiO}_{2}$ : Relationship between the SCR Performance and the Key Factors. Ind. Eng. Chem. Res. 2015, 54, 11011-11023. [CrossRef]

3. Busca, G.; Lietti, L.; Ramis, G.; Berti, F. Chemical and mechanistic aspects of the selective catalytic reduction of $\mathrm{NO}_{x}$ by ammonia over oxide catalysts: A review. Appl. Catal. B 1998, 18, 1-36. [CrossRef]

4. Forzatti, P. Present status and perspectives in de-NO $\mathrm{NO}_{x}$ SCR catalysis. Appl. Catal. A 2001, 222, $221-236$. [CrossRef]

5. Dolanc, G.; Strmčnik, S.; Petrovčič, J. NO $\mathrm{NO}_{x}$ selective catalytic reduction control based on simple models. J. Process. Control 2001, 11, 35-51. [CrossRef]

6. Svachula, J.; Ferlazzo, N.; Forzatti, P.; Tronconi, E.; Bergani, F. Selective reduction of nitrogen oxides $\left(\mathrm{NO}_{x}\right)$ by ammonia over honeycomb selective catalytic reduction catalysts. Ind. Eng. Chem. Res. 1993, 32, 1053-1060. [CrossRef]

7. Chae, H.J.; Choo, S.T.; Choi, H.; Nam, I.S.; Yang, H.S.; Song, S.L. Direct Use of Kinetic Parameters for Modeling and Simulation of a Selective Catalytic Reduction Process. Ind. Eng. Chem. Res. 2000, 39, 1159-1170. [CrossRef]

8. Chen, L.C. Improvement on Hybrid SNCR-SCR Process for NO Control: A Bench Scale Experiment. Aerosol Air Qual. Res. 2006, 6, 30-42. [CrossRef]

9. Nguyen, T.D.B.; Lim, Y.I.; Eom, W.H.; Kim, S.J.; Yoo, K.S. Experiment and CFD simulation of hybrid SNCR-SCR using urea solution in a pilot-scale reactor. Comput. Chem. Eng. 2010, 34, 1580-1589. [CrossRef]

10. Lietti, L.; Nova, I.; Tronconi, E.; Forzatti, P. Transient kinetic study of the SCR-DeNO $\mathrm{S}_{x}$ reaction. Catal. Today 1998, 45, 85-92. [CrossRef]

11. Bosch, H.; Janssen, F. Formation and Control of Nitrogen Oxides. Catal. Today 1988, 2, 369-506.

12. Wang, D.; Hui, S.; Liu, C.; Shang, T.; Zou, H.; Zhang, G. Effect of the shape of SCR reaction tower and the internal guiding plates on the airflow uniformity. Energy Procedia 2014, 61, 398-401. [CrossRef]

13. Lei, Z.G.; Wen, C.P.; Chen, B.H. Optimization of Internals for Selective Catalytic Reduction (SCR) for NO Removal. Ind. Eng. Chem. Res. 2011, 45, 3437-3444. [CrossRef] [PubMed]

14. Spiteri, A.; Eggenschwiler, P.D.; Liao, Y.; Wigley, G.; Michalow-Mauke, K.A.; Elsener, M.; Kröcher, O.; Boulouchos, K. Comparative analysis on the performance of pressure and air-assisted urea injection for selective catalytic reduction of $\mathrm{NO}_{x}$. Fuel 2015, 161, 269-277. [CrossRef]

15. Liu, X.; Tan, H.; Wang, Y.; Yang, F.; Mikulčić, H.; Vujanović, M.; Duić, N. Low $\mathrm{NO}_{x}$ combustion and SCR flow field optimization in a low volatile coal fired boiler. J. Environ. Manag. 2018, 220, 30-35. [CrossRef] [PubMed]

16. Gao, Y.; Liu, Q.; Bian, L. Numerical Simulation and Optimization of Flow Field in the SCR Denitrification System on a 600 MW Capacity Units. Energy Procedia 2012, 14, 370-375. [CrossRef]

17. Ye, X.L.; Yang, D. Application of the Flow Simulation for the Optimization Analysis of SCR DeNO $x$ System of Coal Power Plant. Adv. Mater. Res. 2013, 610-613, 1533-1539. [CrossRef]

18. Zhou, H.; Guo, X.; Zhou, M.; Ma, W.; Dahri, M.W.; Cen, K. Optimization of ammonia injection grid in hybrid selective noncatalyst reduction and selective catalyst reduction system to achieve ultra-low $\mathrm{NO}_{x}$ emissions. J. Energy Inst. 2018, 91, 984-996. [CrossRef]

19. Liu, G.; Bao, W.; Zhang, W.; Shen, D.; Wang, Q.; Li, C.; Luo, K.H. An intelligent control of $\mathrm{NH}_{3}$ injection for optimizing the $\mathrm{NO}_{x} / \mathrm{NH}_{3}$ ratio in SCR system. J. Energy Inst.. In press. [CrossRef]

20. Xu, G.; Xu, C.; Yang, Y.P.; Fang, Y.X.; Zhou, L.Y.; Zhang, K. Novel partial-subsidence tower-type boiler design in an ultra-supercritical power plant. Appl. Energy 2014, 134, 363-373. [CrossRef]

21. Xu, G.; Xu, C.; Yang, Y.P.; Fang, Y.X.; Zhou, L.Y.; Yang, Z.P. Thermodynamic and economic analysis of a partially-underground tower-type boiler design for advanced double reheat power plants. Appl. Therm. Eng. 2015, 78, 565-575. [CrossRef]

22. Xu, Y.Y.; Zhang, Y.; Liu, F.N.; Shi, W.F.; Yuan, J.Q. CFD analysis on the catalyst layer breakage failure of an SCR-DeNO $x$ system for a $350 \mathrm{MW}$ coal-fired power plant. Comput. Chem. Eng. 2014, 69, 119-127. [CrossRef]

23. Gan, X.B.; Yao, D.W.; Wu, F.; Dai, J.W.; Wei, L.; Li, X.W. Modeling and simulation of urea-water-solution droplet evaporation and thermolysis processes for SCR systems. Chin. J. Chem. Eng. 2016, 24, 1065-1073. [CrossRef]

24. Lang, E.; Drtina, P.; Streiff, F.; Fleischli, M. Numerical simulation of the fluid flow and the mixing process in a static mixer. Int. J. Heat Mass Transf. 1995, 38, 2239-2250. [CrossRef] 
25. Chen, J.J.; Lan, C.H.; Jeng, M.S.; Xu, T.F. The development of fan filter unit with flow rate feedback control in a cleanroom. Build. Environ. 2007, 42, 3556-3561. [CrossRef]

26. Handbook of ANSYS 17.1; ANSYS Inc: Canonsburg, PA, USA, 2016.

(C) 2019 by the authors. Licensee MDPI, Basel, Switzerland. This article is an open access article distributed under the terms and conditions of the Creative Commons Attribution (CC BY) license (http:/ / creativecommons.org/licenses/by/4.0/). 